\title{
Serum bactericidal resistance of faecal Escherichia coli and bactericidal competence of serum from patients with ulcerative colitis
}

\author{
D A Burke, S A Clayden, A T R Axon
}

\begin{abstract}
A microtitre method was developed to screen Escherichia coli from 48 patients with ulcerative colitis and 25 controls for serum resistance. Bactericidal resistance was indicated by a change in colour of indicator due to acid production by viable organisms and quantitated by a change in absorbance. The method clearly differentiated between organisms confirmed as resistant or sensitive by conventional techniques. Twenty four $(50 \%)$ disease and $14(56 \%)$ control $E$ coli specimens showed serum resistance. Bactericidal competence of sera from patients with ulcerative colitis was assessed by incubating sensitive $E$ coli with sera from 10 patients with ulcerative colitis and pooled normal serum. All sera effectively reduced viable counts to less than $6 \%$ of original inoculum.

This study shows that serum samples from patients with ulcerative colitis are bactericidally competent and that there is no increase in the number of serum resistant $E$ coli in patients with ulcerative colitis.
\end{abstract}

The ability of pathogenic Escherichia coli to adhere to the intestinal mucosa seems to be an essential step for the mediation of disease. ${ }^{1}$ It enables the organism to overcome host defence mechanisms such as peristalsis and mucus trapping, and therefore allows the bowel to be colonised. Escherichia coli isolated from the faeces of patients with ulcerative colitis differ from those organisms present in control isolates in that they are more likely to produce haemolysin and necrotoxin and more commonly possess the ability to dilate rabbit ileal loops. ${ }^{2} \mathrm{~A}$ significant proportion possess a mannose resistant adhesive property ${ }^{34}$ and this raises the possibility that these organisms may have a role in the pathogenesis of ulcerative colitis.

In ulcerative colitis blood and serum exude from the inflamed mucosa into the lumen of the bowel. The lethal effect of human serum for Gram negative bacteria is well recognised ${ }^{5}$ and seems to have an important role in host defence. This bactericidal activity is mediated by activation of the complement system, which property is lost when complement is inactivated or depleted. Resistance of bacteria to the bactericidal action of human serum has been shown in many pathogenic strains, particularly invasive strains $\mathrm{s}^{67}$ and those causing urinary tract infections. ${ }^{8}$

The ability to resist the lethal effects of human serum might confer an advantage on faecal $E$ coli in ulcerative colitis and might explain the presence of adhesive and invasive strains $^{3}$ in the faeces of patients with the disease. Conversely, the possibility of a defect in the bactericidal competence of serum in patients with ulcerative colitis must also be considered.

The aims of this study were to determine whether $E$ coli from patients with ulcerative colitis show increased resistance to the lethal action of human serum and to assess the bactericidal competence of sera from patients with ulcerative colitis on $E$ coli.

The currently accepted methods for determining the resistance of bacteria to sera are time consuming, laborious, and require large amounts of culture media and sera. ${ }^{5}$ We used a simple screening method, a rapid microtitre technique, which enables many strains to be tested simultaneously using minimal quantities of sera and media.

\section{Methods}

Normal human serum was obtained from 10 healthy male and female volunteers who were not receiving antibiotics. The sera were pooled and stored in $2 \mathrm{ml}$ aliquots at $-70^{\circ} \mathrm{C}$ until required. Serum obtained from patients with ulcerative colitis was used both individually and pooled, but in all cases it was used on the same day as it was collected.

Control sera were prepared by inactivating complement by heating to $56^{\circ} \mathrm{C}$ for 30 minutes and this was included in all assays.

Serum bactericidal assays were performed according to the method of Taylor et al using an incubation medium containing $75 \%$ (v/v) serum. Organisms to be tested were harvested by centrifugation at $3000 \mathrm{rpm}$ from a mid log phase culture in nutrient broth No 2 (Oxoid) as determined by an absorbance reading of 0.5 at $578 \mathrm{~nm}$ using an SP-600 spectrophotometer (Pye Unicam, Cambridge). The cell pellet was washed in veronal buffered saline (VBS, complement fixation diluent, Oxoid) and resuspended in VBS to a final concentration of about $10^{\circ} \mathrm{cells} / \mathrm{ml}$. The bacterial suspension $(0.2 \mathrm{ml})$ was added to $0.6 \mathrm{ml}$ of serum in a sterile bijoux and incubated at $37^{\circ} \mathrm{C}$ for three hours. The number of viable organisms was determined by the method of Miles and Misra ${ }^{10}$ at time intervals of zero, one, two and three hours. 


\section{RAPID MICROTITRE METHOD}

This assay was a modification of the method reported by Moll et al. ${ }^{11}$ Test organisms were grown overnight in nutrient broth No 2 (Oxoid) at $37^{\circ} \mathrm{C}$. The culture $(0.1 \mathrm{ml})$ was inoculated into $10 \mathrm{ml}$ of fresh prewarmed nutrient broth and incubated with shaking at $37^{\circ} \mathrm{C}$ to mid log phase. This culture $(1 \mathrm{ml})$ was harvested, washed once in VBS, and resuspended in $0.5 \mathrm{ml} \mathrm{VBS}$.

The bactericidal assay was carried out in a peptone/glucose/serum broth prepared by adding $2 \mathrm{ml}$ of sterile peptone/glucose broth $(1 \% \mathrm{w} / \mathrm{v}$ glucose, $1 \% \mathrm{w} / \mathrm{v}$ peptone) to $8 \mathrm{ml}$ of serum. Phenol red $(50 \mu \mathrm{l})(1.5 \% \mathrm{v} / \mathrm{v}$ in sterile distilled water) was aseptically added to the broth. Aliquots $(100 \mu \mathrm{l})$ of serum broth were inoculated into the wells of a microtitre tray. The test bacterial suspension $(20 \mu \mathrm{l})$ was added to the serum to give a final serum concentration of $66 \%$. The microtitre trays were incubated at $37^{\circ} \mathrm{C}$ for three hours and the results read by eye and by determining the change in absorbance (as an indicator of growth) using a Titertek Multiscan MC (Flow Laboratories). A positive result was noted when the colour of the indicator changed from red to yellow, brought about by a change in $\mathrm{pH}$ secondary to acid production by viable organisms. Growth was indirectly indicated by an increase in absorbance read by the Multiscan at $450 \mathrm{~nm}$. Several control wells with serum broth and heat killed bacteria were randomly situated around the tray act as a reference for baseline absorbance readings with which wells containing the test organisms could be compared. For each strain tested a control was included using serum where the complement had been heat inactivated.

\section{BACTERIAL STRAINS}

Faecal $E$ coli isolated from 48 patients with ulcerative colitis and 25 from controls were stored on Dorset egg medium slopes at room temperature and protected from light, pending analysis.

$E$ coli $\mathrm{C} 10,{ }^{12}$ a recognised serum resistant strain, and $E$ coli UB281, ${ }^{13}$ a known serum sensitive strain, were included as bacterial controls.

Student's $t$ test was used to test the significance of differences between means and the $\chi^{2}$ test to determine any significance between the number of isolates showing serum resistance in the different groups.

\section{Results}

The response to incubation with $75 \%$ pooled normal serum of the control strains $\mathrm{C10}$ and UB281 was confirmed by the method of Taylor et al. ${ }^{9}$ Figure 1 shows the continued growth of C10 but shows that UB281 is rapidly killed within one hour of incubation with human serum.

Using the microtitre method, visual inspection at three hours showed a noticeable change in colour of the indicator from red to yellow for $E$ coli $\mathrm{C} 10$ but no apparent change in colour for UB281.

To determine whether the microtitre

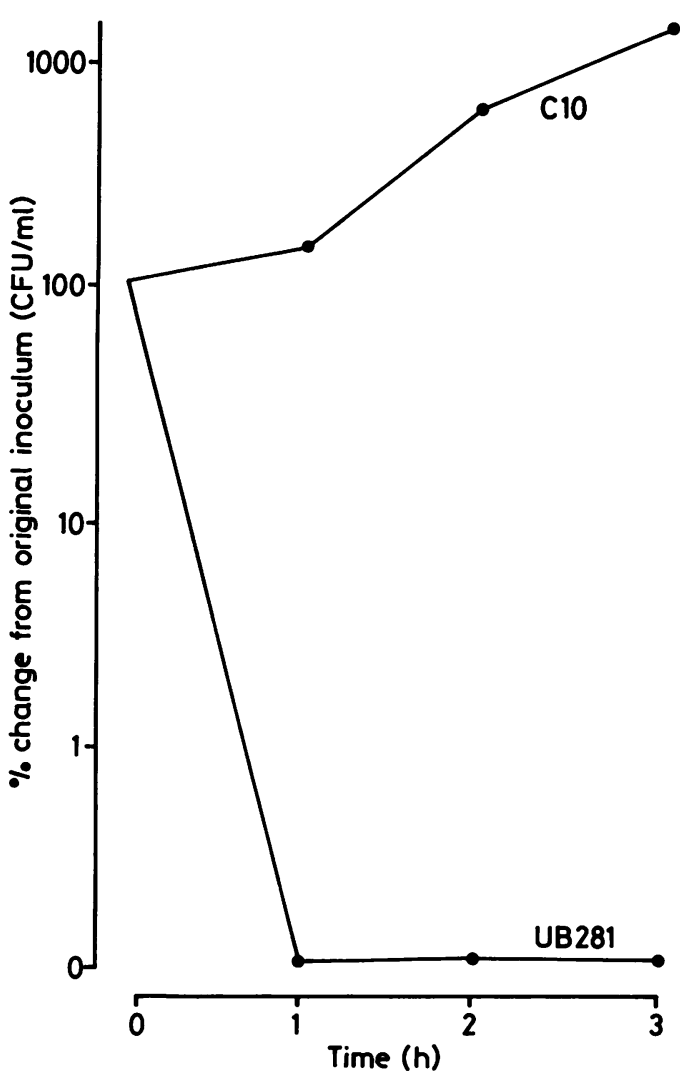

Figure 1 The percentage of the original inoculum viable after one, two, and three hours' incubation with $75 \%$ pooled human serum for the control serum sensitive strain UB281 and serum resistant strain C10.

method could reliably differentiate between serum sensitive and serum resistant $E$ coli 20 separate assays were carried out using the control strains. The change in absorbance after incubation for three hours in the presence of $66 \%$ pooled normal human serum clearly differentiated between strains $\mathrm{C} 10$ (mean (SD) $0.43(0.07) ; 99 \%$ confidence interval 0.39 to $0.47)$ and UB281 ( $-0.01(0.04), 99 \%$ CL 0.01 to -0.04$) \mathrm{p}<0.0001$ (fig 2).

On the basis of these findings strains of unknown serum sensitivity were tested. Where the change in absorbance after three hours fell within 2 standard deviations of the mean change in absorbance of UB281 these strains were classified as serum sensitive. Any strains with a change in absorbance of greater than 2 standard deviations of the mean obtained for UB281 but less than 2 standard deviations of the mean of $\mathrm{C} 10$ were classed as equivocal and the serum sensitivity of these strains was confirmed by the method of Taylor et al. ${ }^{9}$ Those strains showing a change in absorbance within or greater than 2 standard deviations of the mean change in absorbance of $\mathrm{Cl} 0$ were considered to be serum resistant.

Five of the 48 colitic isolates and five of the control isolates gave equivocal results. Two (one disease isolate, one control isolate) were subsequently classed as being serum resistant, with the remainder all being serum sensitive as determined by Taylor's method. Twenty four $(50 \%)$ isolates from patients with ulcerative colitis and $14(56 \%)$ of the control $E$ coli isolates were finally classified as showing in vitro serum resistance (not significant, $\chi^{2}$ test). 
Figure 2 The change in absorbance at $450 \mathrm{~nm}$ after incubation for three hours in the presence of $66 \%$ serum for strains $\mathrm{C} 10$ and UB281. Mean (-) of 20 individual assay (O).

Figure 3 Serum bactericidal assay (Taylor's method). The effect of $75 \%$ colitic and pooled normal human serum on five different serum sensitive $E$ coli. Control strain UB281 (ם).

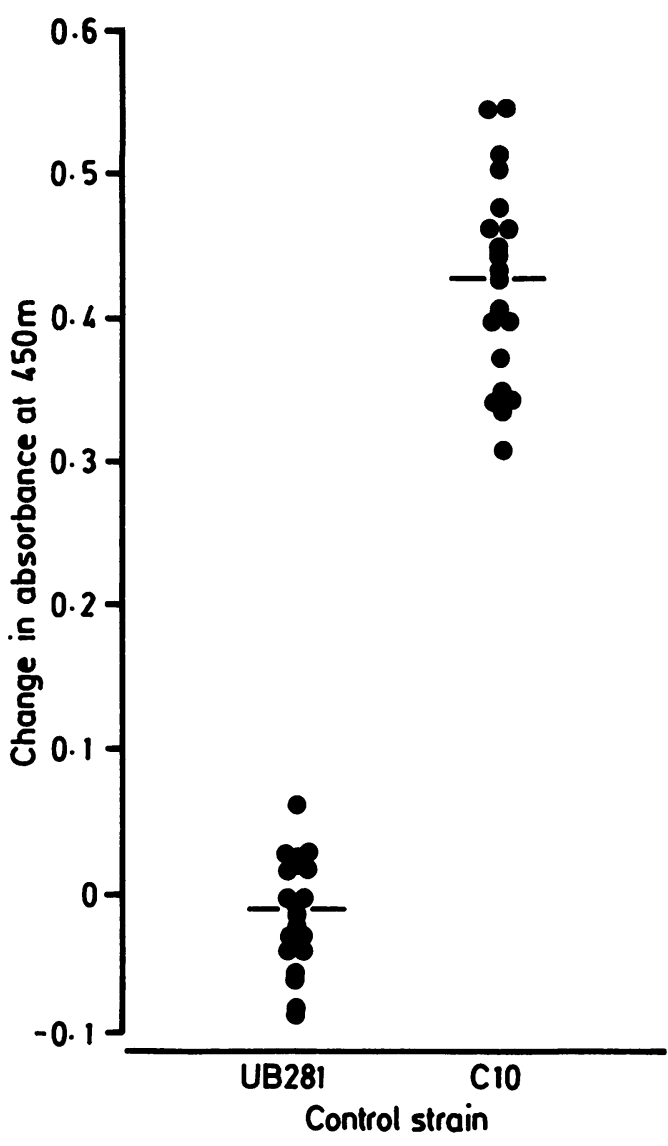

To confirm the results obtained by the microtitre method 15 isolates (five from 'controls, 10 from patients with ulcerative colitis) were studied. Seven were considered to be serum resistant and eight serum sensitive by the microtitre method; this classification was confirmed by the method of Taylor et al. ${ }^{9}$

To investigate the bactericidal competence of serum from patients with ulcerative colitis UB281 and four $E$ coli isolates from patients with ulcerative colitis known to be sensitive to

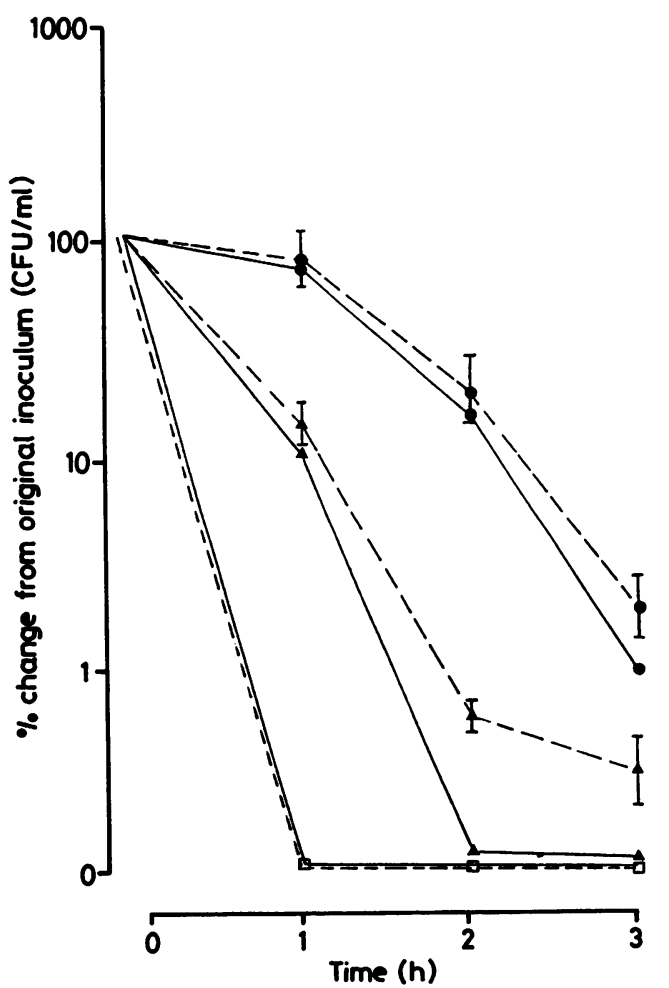

normal human serum were assayed against sera from 10 patients with ulcerative colitis, using the method of Taylor et al. In each assay a control with heat inactivated sera was included. The mean percentage of the original inoculum remaining viable after one, two, and three hours' incubation with disease serum and pooled normal human serum is shown in fig 3 . Although there was more variation in the percentage of the original inoculum viable after incubation with disease sera, in all cases less than $6 \%$ of the inoculum remained viable, indicating that all strains were effectively killed by all disease sera in vitro.

\section{Discussion}

The ability to study large numbers of bacteria for serum resistance has traditionally been limited by laborious and time consuming methods. Screening methods that have been proposed include plaque assay techniques on agar plates ${ }^{7}$ but agar itself may have an anticomplement like effect. The detection of radiolabelled lipopolysaccharide released from bacteria susceptible to serum ${ }^{14}$ is limited by the observation that this occurs even when using heat inactivated serum. We adapted the method of Moll, Cabello, and Timms ${ }^{11}$ which relies on the detection of a change in colour of a $\mathrm{pH}$ dependent indicator. This method does not rely on viable counting techniques with their inherent disadvantages and has proved to be a simple, rapid and reliable method, useful for screening several strains simultaneously.

Using recognised serum sensitive and resistant strains it was possible to define a range for the change in absorbance that would reliably differentiate between sensitive and resistant $E$ coli. There are limitations with this method in that it detects only organisms that continue to grow in the presence of serum. It will not distinguish between the different patterns of

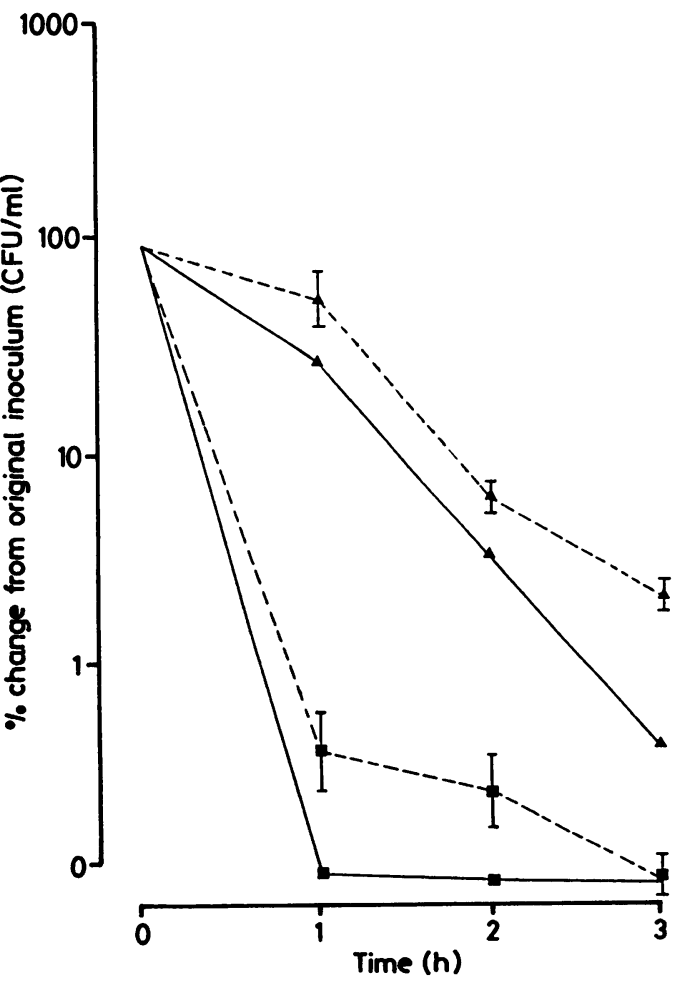


serum resistance that can be identified by conventional means. ${ }^{9}$

The lethal effect of serum for bacteria is well recognised. ${ }^{5}$ The importance of this as a host defence mechanism is most convincingly shown by patients with congenital complete or near complete absence of some of the components of the complement system ${ }^{15-17}$ who show an increased susceptibility to infection. Patients with ulcerative colitis have no quantitative deficiency in the components of the complement system, ${ }^{18}$ but no studies have been reported which have examined the functional bactericidal competence of serum in these patients.

Serum bactericidal activity is said to be reduced in patients with pyelonephritis, ${ }^{19}$ a condition in which Gram negative bacteria with adhesive properties are involved, ${ }^{20}$ and in patients with sickle cell disease in whom the bactericidal action of their serum against Salmonella typhimurium seems to be deficient. ${ }^{21}$

It is therefore equally important to investigate the capacity of the patient's serum to kill susceptible organisms when investigating the role of bactericidal resistance in a disease. The data from this study show that there is no functional deficiency in the capacity of serum from patients with ulcerative colitis to kill $E$ coli in vitro.

$E$ coli with adhesive properties are found in the faeces of patients with ulcerative colitis ${ }^{3-4}$ but it is not known whether their presence is related to the disease process itself or its treatment. Treatment with sulphasalazine does not select for adhesive strains of $E$ coli in ulcerative colitis, ${ }^{22}$ and despite the theoretical selection pressure imposed by the presence of blood and serum in the bowel it does not result in an increase in the proportion of $E$ coli showing serum resistance.

In vitro tests do not always represent the in vivo situation. In this study the bactericidal assays were performed under optimal conditions for the detection of serum resistance. These conditions may not prevail in vivo. Transmissable plasmid mediated factors which are said to confer serum resistance ${ }^{23}$ may only be effective in the presence of small quantities of serum and the concentration used in vitro may exceed that within the lumen of the colon. Cells in the log phase of growth are more susceptible to the bactericidal effects of serum, ${ }^{24}$ and cell sensitivity is known to vary with cultural conditions, ${ }^{25}$ each of these factors may result in an underestimate of in vivo serum resistance. Nevertheless, this study has shown no apparent difference in in vitro serum resistance between faecal $E$ coli from patients and controls.

This study shows that the serum in patients with ulcerative colitis is functionally competent and that the potentially hostile environment of the colon with ulcerative colitis does not select for $E$ coli exhibiting serum resistance.

1 Levine MM. Escherichia coli that cause diarrhoea: Enterotoxigenic, enteropathogenic, enteroinvasive, enterohaemorrhagic, and enteroadherent. J Infect Dis 1987;155:377-89.

2 Cooke EM. Properties of strains of Escherichia coli isolated from the faeces of patients with ulcerative colitis, patients with acute diarrhoea and normal controls. J Clin Pathol 1968;95:101-13.

3 Dickinson RJ, Varian SA, Axon ATR, Cooke EM. Increased incidence of faecal coliforms with in vitro adhesive and invasive properties in patients with ulcrative colitis. Gut 1980;21:788-92.

4 Burke DA, Axon ATR. Adhesive Escherichia coli in inflammatory bowel disease and infective diarrhoea. Br Med J matory bowel disea

5 Taylor PW. Bactericidal and bacteriolytic activity of serum against Gram-negative bacteria. Microbiol Rev 1983;47:46-83.

6 Roantree RJ, Rantz LA. A study of the relationship of the normal bacteriocidal activity of human serum to bacterial infection. J Clin Invest 1960;39:72-81.

7 Fierer J, Finley F, Braude AI. A plaque assay on agar for detection of gram-negative bacilli sensitive to complement. J Immunol 1972;109:1156-8.

8 Gower PE, Taylor PW, Koutsaimanis KG, Roberts AP Serum bacteriocidal activity in patients with upper and lower urinary tract infections. Clin Sci 1972;43:13-22.

9 Taylor PW, Roberts AP, Gower PE. Evaluation of a technique for the estimation of serum bactericidal activity against Gram-negative organisms. Med Lab Technol 1972;29:272-9.

10 Miles AA, Misra SS. The estimation of the bactericidal power of the blood. J Hyg (Lond) 1938;38:732-48.

11 Moll A, Cabello FC, Timmis KN. Rapid assay for the determination of bacterial resistance to the lethal activity of serum. FEMS Microbiol Letts 1979;6:273-6.

12 Bjorksten B, Bortolussi R, Gothefors L, Quie PG. Interaction of $\mathrm{E}$ coli strains with human serum: lack of relationship to K1 antigen. J Paediatr 1976;89:892-7.

13 Bennett PM, Richmond MH. Translocation of a discrete piece of deoxyribonucleic acid carrying an amp gene between replicans in Escherichia coli. $J$ Bacteriol 1976;126:1-6.

14 Fierer J, Finley F, Braude AI. Release of $15 \mathrm{Cr}$-endotoxin from bacteria as an assay of serum bactericidal activity. $J$ Immunol 1974;112:2184-92.

15 Alper CA, Abramson N, Johnston RB, Jandl JH, Rosen FS. Increased susceptibility to infection associated with abnormalities of complement-mediated functions and of the third component of complement (C3). N Engl J Med 1970;282:349-54.

16 Peter G, Weigert MB, Bissel AR, Gold R, Kreutzer D, McLean RH. Meningococcal meningitis $n$ familial deficiency of the fifth component of complement. deficiency of the fifth
Paediatrics $1981 ; 67: 882-6$.

17 Petersen B, Lee HTJ, Snyderman R, Broks GF. Neisseria meningitidis and Neisseria gonorrhoeae bacteraemia associated with $\mathrm{C} 6, \mathrm{C} 7$, or $\mathrm{C} 8$ deficiency. Ann Intern Med 1979;90:917-20.

18 Hodgson HJF, Potter BJ, Jewell DP. Humoral immune system in inflammatory bowel disease. I. Complement levels. Gut 1977;18:749-53.

19 Kalmanson GM, Herbert E, Guze LB. Serum bactericidal activity in patients with pyelonephritis. $\mathrm{Am} \mathrm{J} \mathrm{Med} \mathrm{Sci}$ 1964;248:285-9.

20 Vaisanan V, Tallgren LG, Makela PH, et al. Mannoseresistant haemagglutination and $P$ antigen recognition are characteristic of Escherichia coli causing primary pyelonephritis. Lancet 1981;ii:1366-9.

21 Hand WL, King NL. Deficiency of serum bactericida activity against Salmonella typhimurium in sickle cel anaemia. Clin Exp Immunol 1977;30:262-70.

22 Burke DA, Clayden SA, Axon ATR. Sulphasalazine does not select for Escherichia coli with adhesive properties in ulcerative colitis. Lancet 1988;ii: 966 .

23 Fietta A, Romero E, Siccardi AG. Effect of some R factors on the sensitivity of rough Enterobacteriaceae to human the sensitivity of rough Enterobacterig. Infect Immun 1977;18:278-82.

24 Davis SD, Wedgwood RJ. Kinetics of the bactericidal action of normal serum on gram-negative bacteria. J Immunol 1965;95:75-9.

25 Taylor PW. The effect of the growth environment on the serum sensitivity of some urinary Escherichia coli strains. FEMS Microbiol Lett 1978;3:119-22. 